\title{
ANALISIS BIAYA-VOLUME-LABA (COST-VOLUME-PROFIT) MULTIPRODUK SEBAGAI ALAT PERENCANAAN LABA PADA PT MARINAL INDOPRIMA DI SUMENEP
}

\author{
DEVI LESTARI PRAMITA PUTRI \\ DEVIA SEPTYAWATI
}

\author{
devi_permai@yahoo.co.id \\ Prodi Akuntansi, Fakultas Ekonomi Universitas Madura
}

\begin{abstract}
Cost-volume-profit analysis (CVP) is a useful tool for companies to measure a profit that will be planned by the company. In addition, by analyzing CVP companies will be easier to plan, control, and make a good decision for the company. This type of research is descriptive quantitative. The data type is Quantitative Data. The data source is Primary Data and Secondary Data. The data collection technique is by interview and documentation. PT. Marinal Indoprima in planning profits for 2016 using the Costvolume-profit analysis method must sell cherry products for 3,026,713 units at a selling price of $R p$ 165,524 and for seaweed products at 9,419 units at a selling price of $R p$ 145,52. Break even point for products of the type of cherry 734,943 units with a nominal value of Rp. 123,742,868,862 and for seaweed type products is 4,773 units with a nominal value of Rp. 698,779,242. Margin Of Safety Cherimen products are Rp. 25,458,992,002, and for seaweed products Rp. 144,434,848. The level of PT Marinal Indoprima's Operating Laverage for 5.86 cherries and 60.83 seaweed products, which means that every $1 \%$ increase in sales revenue will increase the company's profit. Based on the calculation of Shut Down Point, processing of cherry and seaweed products must be stopped if the sale is at the point of closing the business of Rp. 103,893,615,707 (cherimen products) and Rp. 586,664,790 (seaweed products).
\end{abstract}

Keywords: cost-profit-volume, BEP, MoS, Operating leverage, shut down points

\begin{abstract}
ABSTRAK
Analisis Cost-volume-profit (CVP) merupakan alat yang berguna bagi perusahaan untuk mengukur suatu laba yang akan di rencanakan oleh perusahaan. Selain itu dengan menganalisis $C V P$ perusahaan akan lebih mudah merencanakan, mengendalikan, dan mengambil suatu keputusan yang baik bagi perusahaan. Jenis penelitian ini adalah Deskriptif Kuantitatif. Jenis datanya adalah Data Kuantitatif. Sumber datanya adalah Data Primer dan Data Skunder. Teknik pengumpulan data yaitu dengan wawancara dan dokumentasi.PT. Marinal Indoprima dalam perencanaan laba untuk tahun 2016 menggunakan metode analisis Cost-volume-profit harus menjualan produk cherimen sebesar 3.026.713 unit dengan harga jual Rp165.424 dan untuk produk rumput laut sebesar 9.419 unit dengan harga jual Rp145.502. Break even point untuk produk jenis cherimen 734.943 unit dengan nilai nominal Rp 123.742.868.862 dan untuk produk jenis rumput laut adalah 4.773 unit dengan nilai nominal Rp 698.749.242. Margin Of Safety Jenis produk Cherimen adalah $\mathrm{Rp}$ 25.458.992.002, dan untuk produk rumput laut sebesar $\mathrm{Rp}$ 144.434.848. Tingkat Operating Laverage PT Marinal Indoprima untuk cherimen 5,86 dan
\end{abstract}


produk rumput laut 60,83 yang berarti setiap $1 \%$ kenaikan pendapatan penjualan akan menambah laba perusahaan. Berdasarkan perhitungan Shut Down Point, pengolahan produk cherimen dan rumput laut harus dihentikan jika penjualan berada dititik penutupan usaha Rp 103.893.615.707 (produk cherimen) dan sebesar Rp 586.664.790 (produk rumput laut).

Kata Kunci: biaya-volume-laba, BEP, MoS, Operating leverage, shut down point

\section{PENDAHULUAN}

Manfaat sebuah informasi adalah sebagai penentuan program yang akan di jalankan atau di lakukan di masa yang akan datang dan juga sebagai penentuan harga jual, Informasi di sini mempunyai dua fungsi perencanaan yaitu perencanaan jangka pendek dan perencanaan jangka panjang. Perencanaan jangka pendek adalah rencana yang di atur sedimikian rupa dan hasil dari rencana tersebut dapat di nikmati dalam jangka waktu satu tahun. Sedangkan perencanaan jangka panjang adalah rencana yang di atur sedemikian rupa dan hasil dari rencana tersebut dapat di nikmati lebih dari jangka waktu satu tahun. Seorang menejer harus melihat kemungkinan dan kesempatan, baik dalam jangka pendek maupun jangka panjang agar dapat membawa perusahaan lebih baik di masa yang akan datang. Dengan begitu perusahaan akan mendapatkan laba yang sangat memuaskan.

Laba adalah pendapatan dan keuntungan yang diperoleh semata-mata dari kegiatan utama perusahaan atau nilai lebih dari pengurangan jumlah pendapatan dengan jumlah biaya. Mendapatkan laba semaksimal mungkin adalah tujuan dan hal yang sangat di harapkan oleh sebuah perusahaan agar dapat berlanjut atau tidak. Selain itu, perencanaan laba dapat membantu perusahaan dalam memilih sebuah alternatif yang berguna untuk meningkatkan laba agar tidak mendapat kerugian di masa yang akan datang. Banyak metode dalam melakukan perencanaan laba diperusahaan. Salah satunya adalah dengan metode Cost-volume-profit (CVP). Cost-volume-profit (CVP) bermanfaat bagi perusahaan untuk menentukan pengambilan sebuah keputusan yang baik bagi perusahaan.

Analisis Cost-volume-profit (CVP) merupakan alat yang berguna bagi perusahaan untuk mengukur suatu laba yang akan di rencanakan oleh perusahaan. Selain itu dengan menganalisis Cost-volume-provit (CVP), perusahaan akan lebih mudah merencanakan, mengendalikan, dan mengambil suatu keputusan yang baik bagi perusahaan. Dengan begitu perusahaan lebih mudah dalam merencanakan apa yang akan dilakukan pada masa yang akan datang agar dapat bersaing dengan perusahaan lain dan tidak mengalami kebangkrutan.

Sesuai dengan latar belakang di atas, maka rumusan masalah dalam penelitian ini adalah Bagaimana penerapan Biaya-Volume-Laba sebagai alat ukur dalam merencanakan laba di PT. Marinal Indoprima di Sumenep.

\section{TINJAUAN PUSTAKA}

\section{Pengertian akuntansi manajemen}

Menurut Kusnadi, dkk (2005;8) Akuntansi manajemen adalah suatu seni atau keterampilan mengolah berbagai kejadian atau transaksi keuangan atau yang dapat diukur dengan uang menjadi berbagai laporan yang di butuhkan oleh pihak manajemen yang akan digunakan untuk merencanakan, mengorganisir, melaksanakan dan mengawasi berbagai aktivitas yang ada dalam organisasi bisnis dengan tujuan untuk memaksimalkan laba serta membantu manajemen di dalam mengambil berbagai keputusan bisnis. 


\section{Perencanaan Laba}

Menurut Carter Usry $(2005 ; 4)$ Perencanaan Laba (Profit Planning) adalah pengembangan dari suatu rencana operasi guna mencapai cita-cita dan tujuan perusahaan. Laba adalah penting dalam perencanaan karena tujuan utama dari suatu rencana adalah laba yang memuaskan.

\section{Ramalan Penjualan}

Menurut Zulian Yamit (2003;44-57) Peramalan (Forecasting) merupakan alat bantu yang penting dalam perencanaan yang efektif dan efesien khususnya dalam bidang ekonomi.

Untuk menentukan Ramalan Penjualan ada banyak metode yang digunakan, diantaranya Metode Kuadrat Terkecil (Least Quares Method) dengan rumus sebagai berikut:

$$
y=a+b x \quad a=\frac{\Sigma y}{n} \quad b=\frac{\Sigma x y}{\Sigma x^{2}}
$$

Dimana :

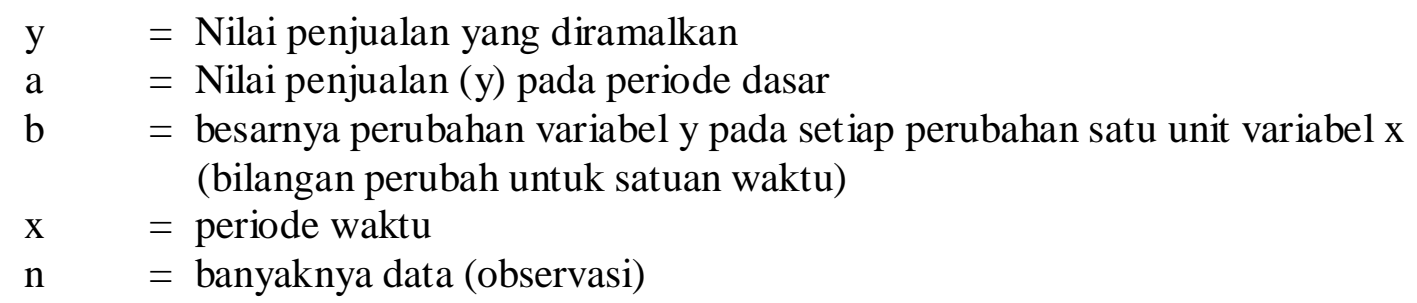

\section{Estimasi Harga Jual dan Bahan Baku}

Untuk menghitung estimasi harga jual dan bahan baku menggunakan rata-rata ukur (arithmetic mean). Menurut Riduwan (2009;108-109) kegunaan rata-rata ukur antara lain mencari rata-rata kenaikan dalam bentuk presentase, perbandingan tiap data berurutan yang hampir tetap, menghitung rata-rata terhadap persentase atau ratio perubahan suatu gejala pada data tertentu. Rata-rata ukur dinyatakan dengan rumus:

$\log \mathrm{RU}=\frac{\Sigma \log X i}{n}$

Keterangan :

RU = Rata-rata ukur

$\mathrm{Xi} \quad=$ Nilai pengamatan

$\mathrm{n} \quad=$ banyak data

\section{Anggaran Produksi}

Menurut Carter Usry (2005;17-18) Anggaran produksi berurusan dengan penjadwalan operasi, penentuan volume, dan penetapan kuantitas maksimum dan minimum dari persediaan. Suatu anggaran produksi dinyatakan dalam unit fisik.

Unit yang di perlukan untuk memenuhi anggaran penjualan $\quad \mathrm{xxx}$

Ditambah persediaan akhir yang di inginkan $\quad \underline{\mathrm{xxx}}$

Total unit yang diperlukan $\quad \mathrm{xxx}$

Dikurangi persediaan awal $\quad \underline{\mathrm{xxx}}$

Produksi yang direncanakan untuk tahun ini $\quad \underline{\mathrm{xxx}}$

\section{Mengalokasikan Biaya Bersama}

Menurut Bastian Bustami dan Nurlela (2007;178-179) dalam alokasi biaya dapat digunakan beberapa metode, diantaranya Metode Harga Pasar (Nilai Jual). Metode harga 
pasar atau nilai jual merupakan pembebanan biaya bersama atas dasar nilai jual masingmasing produk.

Rumus:

Pembebanan $=\frac{\text { jumlah nilai jual masing }- \text { masing produk }}{\text { jumlah nilai jual keseluruhan produk }} X$ biaya bersama

\section{Menyusun Laporan laba-Rugi}

Untuk menyusun laporan laba rugi ada dua cara yaitu dengan pendekatan Full Costing dan Variabel Costing. Menurut Samryn (2013;72) cara menyusun laporan laba rugi dengan cara sebagai berikut:

Penjualan

Biaya-Biaya Variabel

Margin Kontribusi

Biaya-Biaya Tetap

Laba Bersih

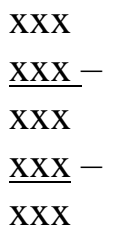

\section{Analisis Cost-Volume-Profit (CVP)}

Ray H. Garrison dan Eric W. Noreen (2000;250-251) menyatakan Analisis BiayaVolume-Laba adalah alat yang sangat berguna bagi manajer untuk menjalankan fungsinya. Alat ini membantu mereka untuk memahami hubungan antara biaya, volume dan laba organisasi dengan memfokuskan hubungan lima elemen berikut; (1) Harga produk, (2), Volume atau tingkat aktivitas, (3) Biaya variabel per unit, (4) Total biaya tetap, (5) Bauran produk yang dijual.

Karena analisis Biaya-Volume-Laba membantu manajer untuk memahami hubungan antara biaya, volume dan laba, alat analisis ini sangat berguna dalam proses pembuatan keputusan. Keputusan ini termasuk produk apa yang akan dibuat atau dijual, bagaimanakah kebijakan penentuan harganya, apakah strategi pemasaran yang digunakan, tipe fasilitas produksi apa yang diperlukan.

\section{Margin Kontribusi (MK)}

Menurut Rudianto (2013;27-28) Margin kontribusi adalah selisih antara nilai penjualan dengan biaya variabelnya. Jumlah tersebut akan digunakan untuk menutup biaya tetap dan menghasilkan laba periode tersebut. Semakin besar margin kontribusi yang diperoleh perusahaan dari setiap unit produk yang dijualnya, semakin cepat perusahaan menutup biaya tetapnya dan mencapai laba yang diinginkan. Semakin kecil margin kontribusi yang dihasilkan dari setiap unit produk yang dihasilkannya, semakin lama perusahaan menutup biaya tetapnya dan mencapai laba yang diinginkan. Rasio ini dihitung dengan cara:

Rasio margin kontribusi $=\frac{\text { margin kontribusi }}{\text { penjualan }} \times 100 \%$

\section{Break even point (BEP) atau Titik impas}

Samryn (2013;174-176) menyatakan titik impas merupakan tingkat aktivitas di mana suatu organisasi tidak mendapat laba dan juga tidak menderita rugi. Dalam suatu grafik, titik impas dapat ditemukan pada titik perpotongan garis pendapatan dan garis total biaya. Titik impas berada pada posisi total pendapatan sama dengan total biaya atau sebagai tingkat penjualan dimana total margin kontribusi sama dengan total biaya tetap. 
Metode margin kontribusi. Metode ini merupakan penyingkatan dari formula metode persamaan dalam menghitung titik impas. Hal itu terlihat pada formula dibawah ini:

$$
\begin{aligned}
& \text { Impas dalam unit }=\frac{\text { Biaya Tetap }}{\text { Margin Kontribusi per unit }} \\
& \text { Impas dalam Rp }=\frac{\text { Biaya Tetap }}{\text { Rasio Margin Kontribusi }}
\end{aligned}
$$

\section{Margin of safety (MOS) atau Margin keamanan}

Menurut Don R. Hansen dan Maryanne M. Mowen (2005;297) Margin penngaman (Margin Of Safety) adalah unit yang terjual atau diharapkan untuk terjual atau pendapatan yang dihasilkan atau diharapkan untuk dihasilkan yang melebihi volume impas. Perhitungan dapat dinyatakan dalam unit, suatu uang, dan persentase. Rumus Margin of safety (MOS) atau Margin keamanan:

Margin Keamanan =total penjualan-titik impas

Dengan mengetahui titik margin keamanan tersebut maka manjemen dapat merumuskan berbagai strategi, taktik, dan langkah-langkah operasional untuk bertahan agar penjualan tidak mengalami abrasi sampai melebihi angka margin keamanan.

\section{Leverage operasi}

Leverage operasi merupakan suatu ukuran kemampuan manajemen memanfaatkan biaya tetap dalam suatu organisasi agar mencapai tingkat laba tertentu. Model ini dapat digunakan untuk menjawab pertanyaan tentang berapa besarnya kenaikan laba jika terjadi kenaikan penjualan dalam jumlah persentase tertentu. Samryn $(2013 ; 182)$. Factor leverage operasi diukur dengan angka absolut dan memengaruhi sensitivitas laba bersih terhadap perubahan penjualan. Tingkat leverage operasi dapat dihitung dengan menggunakan formula :

$$
\text { Tingkat Leverage operasi }=\frac{\text { margin kontribusi }}{\text { laba bersih }}
$$

\section{Shut Down Point (SDP) atau Titik penutupan usaha}

Samryn (2013;186-187) menyatakan bahwa Sebuah perusahaan dapat dipertimbangkan untuk ditutup bila hasil penjualan sudah tidak dapat lagi menutup biaya tetap tunai atau biaya tetap yang segera memerlukan pengeluaran kas. Hal itu disebabkan kelanjutan usaha atau produksi harus dibiayai dari sumber dana lain yang berasal dari luar perusahaan. Sumber dana seperti ini umumnya juga menimbulkan tambahan beban biaya tunai. Hasil penjualan yang mengharuskanpenutupan usaha dalam rupiah dan dalam unit, masing-masing yang dapat dihitung dengan rumus sebagai berikut :

Titik penutupan usaha $=\frac{\text { biaya tetap tunai }}{\text { rasio margin kontribusi }}$

\section{Analisis Target Laba}

Ray H. Garrison dan Eric W. Noreen (2000;262-263) menyatakan bahwa Rumusan biaya-volume-laba dapat digunakan untuk menentukan volume penjualan untuk mencapai target laba. Ada dua cara untuk melakukan analisis target laba yaitu:

1. Menggunakan metode persamaan

$$
\text { Penjualan }=\text { Biaya variabel }+ \text { Biaya tetap }+ \text { Laba }
$$


2. Menggunakan pendekatan margin kontribusi

Unit penjualan untuk mencapai target laba $=\frac{\text { biaya tetap }+ \text { target laba }}{\text { margin kontribusi per unit }}$

\section{METODOLOGI PENELITIAN}

Jenis penelitian yang dilakukan oleh penelitian ini menggunakan metode deskriptif kuantitatif. Jenis data yang di gunakan dalam penelitian ini adalah Data kuantitatif. Sumber data yang digunakan dalam penelitian ini adalah. Data primer, yaitu data Laporan Labarugi dan Laporan Harga pokok produksi yang secara langsung diperoleh dari perusahaan yang akan diteliti. Data sekunder, yaitu data yang diperoleh dari luar perusahaan berupa buku-buku yang di bahas pada landasan teori peneliti.

Metode analisis data dalam penelitian ini yaitu:

1. Menentukan laba yang akan direncanakan.

a. Ramalan Penjualan

b. Estimasi harga jual dan bahan baku menggunakan metode Arimetric mean

c. Mengalokasikan biaya bersama.

d. Untuk mengalokasikan biaya bersama adalah berdasarkan pada metode nilai jual masing-masing produk bersama yang dijual atau yang di hasilkan.

e. Menentukan dan mengetahui laba yang direncanakan untuk tahun 2016

f. Menyusun proyeksi laporan laba rugi dengan pendekatan Variabel Costing.

Penjualan

$\mathrm{XXX}$

Biaya-Biaya Variabel

$\underline{\mathrm{XXX}}$

Margin Contribusi

$\mathrm{XXX}$

Biaya-Biaya Tetap

$\underline{\mathrm{XXX}}-$

Laba bersih

$\mathrm{XXX}$

2. Menentukan margin kontribusi,, break even point, margin of safety, operating leverage, dan shut down point.

a. Margin kontribusi (MK)

b. Break Even Point (BEP) atau Titik Impas

c. Margin Of Safety (MOS)

d. Operating Laverage

e. Shut Down Point atau Titik Penutupan Usaha

3. Analisis Target Laba menggunakan :

Metode pendekatan margin kontribusi.

Unit penjualan untuk mencapai target laba $=\frac{\text { biaya tetap }+ \text { target laba }}{\text { margin kontribusi per unit }}$

HASIL DAN PEMBAHASAN

Pembahasan 
PT. Marinal Indoprima memiliki dua jenis produk yaitu Cherimen dan Rumput Laut. Cherimen merupakan ikan teri hasil dari sektor kelautan dan rumput laut merupakan salah sumber daya hayati yang terdapat di wilayah pesisir dan laut. Data unit produksi per tahun untuk Cherimen dan Rumput laut selama tahun 2011-2015.

Tabel 1 Data produksi Cherimen dan Rumput Laut Tahun 2011-2015

\begin{tabular}{cccccc}
\hline \multirow{2}{*}{ Jenis Produk } & \multicolumn{5}{c}{ Tahun } \\
\cline { 2 - 6 } & $\mathbf{2 0 1 1}$ & $\mathbf{2 0 1 2}$ & $\mathbf{2 0 1 3}$ & $\mathbf{2 0 1 4}$ & $\mathbf{2 0 1 5}$ \\
\hline Cherimen & 415.529 & 491.125 & 569.204 & 661.011 & 768.425 \\
\hline Rumput Laut & 2.730 & 3.208 & 3.699 & 4.274 & 4.946 \\
\hline Jumlah & 418.259 & 494.334 & 572.903 & 665.285 & 773.371
\end{tabular}

Sumber: Data diolah

Untuk membantu kapasitas produksi yang berkelanjutan perusahaan memiliki persediaan yang di simpan di gudang. Rincian persediaan untuk kedua jenis produk.

Tabel 2 Persediaan Produk Tahun 2011-2015 (unit)

\begin{tabular}{ccccc} 
Tahun & \multicolumn{3}{c}{ Jenis Produk } \\
\cline { 2 - 5 } & Awal & Cherimen & Rumput laut \\
\cline { 2 - 5 } & 94 & 10.669 & 0 & Akhir \\
\hline $\mathbf{2 0 1 1}$ & 10.669 & 12.876 & 70 & 70 \\
\hline $\mathbf{2 0 1 3}$ & 12.876 & 15.558 & 101 & 101 \\
\hline $\mathbf{2 0 1 4}$ & 15.558 & 18.820 & 122 & 122 \\
\hline $\mathbf{2 0 1 5}$ & 18.820 & 22.790 & 147 \\
\hline
\end{tabular}

Sumber: PT Marinal Indoprima

Hasil volume penjualan dan perkembangan harga jual serta persediaan barang jadi untuk setiap jenis mulai tahun 2011-2015 untuk kedua jenis produk adalah sebagai berikut:

Tabel 3 Data volume penjualan 2011-2016

\begin{tabular}{cccccc}
\hline \multirow{2}{*}{ Tahun } & \multicolumn{2}{c}{ Produk Jenis Cherimen } & \multicolumn{2}{c}{ Produk Jenis Rumput laut } \\
\cline { 2 - 6 } & Unit & Harga & Unit & \multicolumn{2}{c}{ Harga } \\
\hline $\mathbf{2 0 1 1}$ & 429.447 & Rp140.000 & 2.822 & $\mathrm{Rp}$ & 120.000 \\
\hline $\mathbf{2 0 1 2}$ & 518.298 & $\mathrm{Rp} 145.000$ & 3.386 & $\mathrm{Rp}$ & 125.000 \\
\hline $\mathbf{2 0 1 3}$ & 601.226 & $\mathrm{Rp} 150.000$ & 3.907 & $\mathrm{Rp}$ & 130.000 \\
\hline $\mathbf{2 0 1 4}$ & 701.107 & $\mathrm{Rp} 155.000$ & 4.533 & $\mathrm{Rp}$ & 135.000 \\
\hline $\mathbf{2 0 1 5}$ & 818.433 & $\mathrm{Rp} 160.000$ & 5.267 & $\mathrm{Rp}$ & 140.000 \\
\hline
\end{tabular}

Sumber: PT Marinal Indoprima

Data pengeluaran Biaya Overhead Pabrik, Biaya Pemasaran dan Biaya administrasi dan umum. Pengeluaran perusahaan yang berhubungan dengan proses produksi selain biaya bahan baku dan biaya tenaga kerja langsung.

Tabel 4 Data Biaya Overhead Pabrik (dalam Rupiah) 


\begin{tabular}{cccccc}
\hline Jenis Biaya & $\mathbf{2 0 1 1}$ & $\mathbf{2 0 1 2}$ & $\mathbf{2 0 1 3}$ & $\mathbf{2 0 1 4}$ & $\mathbf{2 0 1 5}$ \\
\cline { 2 - 6 } & 1.036 .753 .475 & 1.295 .941 .844 & 1.555 .130 .213 & 1.866 .156 .255 & 2.239 .387 .506 \\
\hline $\begin{array}{c}\text { Biaya Overhead } \\
\text { Pabrik }\end{array}$ & 699.843 .220 & 874.804 .025 & 1.049 .764 .830 & 1.259 .717 .796 & 1.511 .661 .355 \\
\hline Biaya Pengadaan & 790.620 .077 & 988.275 .096 & 1.185 .930 .116 & 1.423 .116 .139 & 1.707 .739 .366 \\
\hline $\begin{array}{c}\text { Gaji Karyawan } \\
\text { Pabrik Madura }\end{array}$ & 585.434 .898 & 822.521 .877 & 987.026 .252 & 1.184 .431 .503 \\
\hline $\begin{array}{c}\text { Gaji Karyawan } \\
\text { Pabrik Paiton, Gili } \\
\text { Ketapang dan Sarang }\end{array}$ & 548.347 .918 & 623.476 .815 & 988.172 .178 & 1.185 .806 .614 & 1.422 .967 .936 \\
\hline $\begin{array}{c}\text { Biaya Administrasi } \\
\text { Pabrik }\end{array}$ & 658.781 .452 & 1.239 .437 .885 & 1.487 .325 .462 & 1.784 .790 .554 & 2.141 .748 .665 \\
\hline $\begin{array}{c}\text { Bunga Pinjaman } \\
\text { Pihak Ketiga }\end{array}$ & 991.550 .308 & 46.905 .104 & 56.286 .125 & 67.543 .349 & 81.052 .019 \\
\hline $\begin{array}{c}\text { Biaya Overhead } \\
\text { Lain-lain }\end{array}$ & 37.524 .083 & & & & \\
\hline Sumanyyyyy
\end{tabular}

Sumber: PT Marinal Indoprima

Tabel 5 Data biaya pemasaran

(dalam Rupiah)

\begin{tabular}{|c|c|c|c|c|c|}
\hline \multirow{2}{*}{ Jenis Biaya } & \multicolumn{5}{|c|}{ Tahun } \\
\hline & 2011 & 2012 & 2013 & 2014 & 2015 \\
\hline $\begin{array}{l}\text { Freigh, EMKL, } \\
\text { stuffing, dll }\end{array}$ & 656.966 .935 & 821.208 .669 & 1.026 .510 .836 & 1.283 .138 .546 & 1.603 .923 .182 \\
\hline $\begin{array}{l}\text { Biaya Penjualan } \\
\text { Cherimen }\end{array}$ & 289.272 .480 & 361.590 .600 & 451.988 .250 & 564.985 .313 & 706.231 .641 \\
\hline $\begin{array}{l}\text { Biaya Penjualan } \\
\text { Rumput Laut }\end{array}$ & 148.413 .913 & 185.517 .392 & 231.896 .739 & 289.870 .924 & 362.338 .655 \\
\hline
\end{tabular}

Tabel 6 Data administrasi dan umum (dalam Rupiah)

\begin{tabular}{lccccc}
\hline \multirow{1}{*}{ Jenis Biaya } & \multicolumn{5}{c}{ Tahun } \\
\cline { 2 - 6 } & $\mathbf{2 0 1 1}$ & $\mathbf{2 0 1 2}$ & $\mathbf{2 0 1 3}$ & $\mathbf{2 0 1 4}$ & $\mathbf{2 0 1 5}$ \\
\hline $\begin{array}{l}\text { Gaji Karyawan } \\
\text { Surabaya }\end{array}$ & 251.950 .000 & 314.937 .500 & 393.671 .875 & 492.089 .844 & 615.112 .305 \\
\hline $\begin{array}{l}\text { Biaya Gedung } \\
\text { Gresik }\end{array}$ & 498.105 .450 & 622.631 .813 & 778.289 .766 & 972.862 .202 & 1.216 .077 .759 \\
\hline $\begin{array}{l}\text { Biaya Telepon, } \\
\text { Listrik, PDAM }\end{array}$ & 82.238 .786 & 102.798 .483 & 128.498 .103 & 160.622 .629 & 200.778 .286 \\
\hline $\begin{array}{l}\text { Biaya Kantor (ATK } \\
\text { Statonery, dll) }\end{array}$ & 105.930 .146 & 132.412 .683 & 165.515 .853 & 206.894 .816 & 258.618 .521 \\
\hline Bunga Pinjaman & 224.523 .152 & 280.653 .940 & 350.817 .425 & 438.521 .781 & 548.152 .227 \\
\hline Biaya Penyusutan & 395.334 .287 & 494.167 .859 & 617.709 .823 & 772.137 .279 & 965.171 .599 \\
\hline Biaya Lainnya & 466.709 .418 & 583.386 .773 & 729.233 .466 & 911.541 .832 & 1.139 .427 .290 \\
\hline Sumber: PT Marinal Indoprima & & & & & \\
\hline
\end{tabular}

Sumber: PT Marinal Indoprima

\section{Menentukan Ramalan Penjualan dan Harga Jual Produk Tahun 2016}


Ramalan penjualan merupakan dasar dari rencana kegiatan yang akan dilakukan perusahaan. Adapun ramalan penjualan dan harga jual untuk tiap jenis produk adalah sebagai berikut:

Tabel 7 Ramalan Penjualan dan Harga Jual Produk Tahun 2016 (Unit)

\begin{tabular}{|c|c|c|c|}
\hline \\
\hline Jenis & Ramalan & Harga Jual & Penjualan \\
\hline Produk & $\begin{array}{c}\text { Penjualan } \\
\text { (Unit) }\end{array}$ & ( $\mathbf{R p})$ & $(\mathbf{R p})$ \\
\hline Cherimen & 901.936 & Rp 165.424 & Rp 149.201.860.864 \\
\hline Rumput Laut & 5.795 & Rp 145.502 & $\mathrm{Rp} \quad 843.184 .090$ \\
\hline Jumlah & 907.731 & & Rp150.045.044.954 \\
\hline
\end{tabular}

Sumber: Data diolah

Dari tabel diatas diketahui ramalan penjualan untuk produk Cherimen 901.936 unit dengan harga jual Rp 165.424 dan jenis produk Rumput Laut 5.795 unit dengan harga jual Rp 145.502. Total ramalan penjualan 907.731 unit.

\section{Menentukan Tingkat Persediaan}

Sebelum menentukan persediaan akhir produk terlebih dahulu menghitung perputaran persediaan (ITO). Dalam menghitung perputaran persediaan tahun 2016 menggunakan asumsi tingkat perputaran persediaan lima tahun terakhir ( 2011-2016 ). Besar persediaan awal dan persediaan akhir masing-masing produk dapat dilihat pada tabel berikut.

Tabel 8

Persediaan Awal dan Persediaan Akhir Tahu 2016 (unit)

\begin{tabular}{ccc}
\hline Jenis Produk & Persediaan Awal & Persediaan Akhir \\
\hline Cherimen & 22.790 & 23.778 \\
\hline Rumput Laut & 147 & 150 \\
\hline Jumlah & 22.937 & 23.928 \\
\hline
\end{tabular}

Sumber: Data diolah

Dari tabel di atas diketahui tingkat persediaan awal untuk produk cherimen 22.790 unit dan untuk produk rumput laut 147 unit, sedangkan untuk persediaan akhir produk cherimen 23.923 unit dan produk rumput laut 150 unit.

\section{Menentukan Anggaran Produksi}

Anggaran produksi merupakan perencanaan volume barang yang akan di produksi dengan mempertimbangkan persediaan produk jadi agar sesuia dengan tingkat penjualan yang telah direncanakan.

Tabel 9 Rencana produksi tiap jenis produk tahun 2016 (unit)

\begin{tabular}{cccc}
\hline \multirow{2}{*}{ Keterangan } & \multicolumn{2}{c}{ Jenis Produk } & \multirow{2}{*}{ Jumlah } \\
\cline { 2 - 3 } & Cherimen & Rumput laut & \\
\hline Ramalan Penjualan & 901.936 & 5.795 & 907731 \\
\hline Rencanaan persediaan akhir & 23.778 & 150 & 23928 \\
\hline Produk harus tersedia & 925.714 & 5.945 & 931.659 \\
\hline Persediaan awal & 22.790 & 147 & 22937 \\
\hline
\end{tabular}




$\begin{array}{llll}\text { Rencana produksi } & 902.924 & 5.798 & 908.722\end{array}$

Sumber: Data diolah

\section{Komponen Biaya}

\section{Biaya Variabel}

Perhitungan untuk keseluruhan biaya variabel untuk tahun 2016 dapat dilihat pada tabel berikut:

Tabel 10 Biaya-biaya variabel untuk tahun 2016

\begin{tabular}{clc}
\hline No & \multicolumn{1}{c}{ Jenis biaya variabel } & $\begin{array}{c}\text { Biaya variabel } \\
(\mathbf{R p})\end{array}$ \\
\hline $\mathbf{1}$ & Biaya telepon, listrik, PDAM & 240.933 .943 \\
\hline $\mathbf{2}$ & Biaya kantor (ATK Statonery, dll) & 310.342 .226 \\
\hline $\mathbf{3}$ & Biaya lainnya & 1.367 .312 .748 \\
\hline $\mathbf{4}$ & Biaya tenaga kerja langsung & 5.579 .944 .504 \\
\hline $\mathbf{5}$ & Biaya overhead pabrik & 12.003 .819 .741 \\
\hline & Jumlah & 19.502 .353 .162 \\
\hline
\end{tabular}

Sumber: Data diolah

Dari tabel diatas, dapat disimpulkan perkiraan biaya variabel yang akan dikeluarkan untuk tahun 2016 sebesar Rp 19.502.353.162. Perhitungan untuk jumlah biaya tetap tahun 2016 dapat dilihat pada tabel berikut:

Tabel 11 Perhitungan Biaya Tetap

\begin{tabular}{clr}
\hline No & \multicolumn{1}{c}{ Jenis biaya tetap } & \multicolumn{1}{c}{ Biiaya tetap (Rp) } \\
\hline $\mathbf{1}$ & Freigh, EMKL, stuffing, dll & 1.924 .707 .818 \\
\hline $\mathbf{2}$ & Biaya penjualan cherimen & 847.477 .969 \\
\hline $\mathbf{3}$ & Biaya penjualan rumput laut & 434.806 .386 \\
\hline $\mathbf{4}$ & Gaji karyawan Surabaya & 738.134 .766 \\
\hline $\mathbf{5}$ & Biaya gedung gresik & 1.459 .293 .316 \\
\hline $\mathbf{6}$ & Bunga pinjaman & 657.782 .673 \\
\hline $\mathbf{7}$ & Biaya penyusutan & 1.158 .205 .919 \\
\hline & Jumlah & 7.220 .408 .847 \\
\hline
\end{tabular}

Sumber: Data diolah

Dari tabel diatas, dapat disimpulkan perkiraan biaya tetap yang akan dikeluarkan untuk tahun 2016 sebesar Rp 7.220.408.847

\section{Pengalokasian biaya}

Masalah yang dihadapi oleh PT. Marinal Indoprima yang menghasilkan produk bersama yaitu pengalokasian biaya pada masing-masing produknya. Perusahaan biasanya ingin mengetahui bersama besarnya kontribusi masing-masing produk tersebut, jenis mana yang menguntungkan atau jenis yang perlu didorong pemasarannya. Artinya bahwa perusahaan perlu mengetahui seteliti mungkin bagian dari seluruh biaya yang dibebankan kepada masing-masing produk. Berdasarkan tabel 12 diketahui biaya variable pada masing-masing produk per unit pada produk jenis cherimen adalah sebesar Rp 21.469,5/unit dan produk jenis Rumput laut adalah sebesar Rp 20.213/unit. 
Tabel 12 Perhitungan alokasi biaya variabel tahun 2016

\begin{tabular}{lrcrrrr}
\hline Jenis Produk & $\begin{array}{c}\text { Produksi } \\
\text { (unit) }\end{array}$ & $\begin{array}{c}\text { Harga Jual } \\
\text { per Unit } \\
(\mathbf{R p})\end{array}$ & Nilai jual (Rp) & $\begin{array}{c}\text { Nilai jual } \\
\text { relatif } \\
(\boldsymbol{\%})\end{array}$ & $\begin{array}{c}\text { Alokasi biaya } \\
\text { bersma }\end{array}$ & $\begin{array}{c}\text { Biaya } \\
\text { produksi } \\
\text { per unit }\end{array}$ \\
\hline Cherimen & 902.924 & 165.424 & 149.365 .299 .776 & 99,4 & 19.385 .339 .043 & $21.469,5$ \\
\hline Rumput laut & 5.789 & 145.502 & 842.311 .078 & 0,6 & 117.014 .119 & 20.213 \\
\hline Jumlah & 908.722 & 310.926 & 150.207 .610 .854 & 100 & 19.502 .353 .162 & $41.541,5$ \\
\hline
\end{tabular}

Sumber: Data diolah

Jadi, jumlah keseluruhan biaya variabel pada produk per unit adalah sebesar Rp 41.541,5/unit. Biaya variabel pada masing-masin produk untuk produk jenis cherimen adalah sebesar Rp 19.385.339.043 dan produk jenis rumput laut adalah sebesar Rp 117.014.119 Jadi, jumlah keseluruhan biaya variabel pada produk adalah sebesar Rp 19.502.353.162

Tabel 13 Perhitungan alokasi biaya tetap tahun 2016

\begin{tabular}{lrrrrrr}
\hline Jenis Produk & $\begin{array}{c}\text { Produksi } \\
\text { (unit) }\end{array}$ & $\begin{array}{c}\text { Harga Jual } \\
\text { per Unit } \\
\text { (Rp) }\end{array}$ & Nilai jual(Rp) & $\begin{array}{c}\text { Nilai jual } \\
\text { relatif (\%) }\end{array}$ & $\begin{array}{c}\text { Alokasi } \\
\text { biaya bersma }\end{array}$ & $\begin{array}{c}\text { Biaya } \\
\text { produksi } \\
\text { per unit }\end{array}$ \\
\hline Cherimen & 902.924 & 165.424 & 149.365 .299 .776 & 99,4 & 7.177 .086 .394 & 7.949 \\
\hline Rumput laut & 5.789 & 145.502 & 842.311 .078 & 0,6 & 43.322 .453 & $7.483,5$ \\
\hline Jumlah & 908.722 & 310.926 & 150.207 .610 .854 & 100 & 7.220 .408 .847 & $15.432,5$ \\
\hline
\end{tabular}

Sumber: Data diolah

Diketahui biaya tetap pada masing-masing produk per unit pada produk jenis cherimen adalah $\mathrm{Rp} 7.949$ /unit dan produk jenis rumput laut adalah Rp 7.483,5/unit. Jadi, jumlah keseluruhan biaya tetap pada masing-masing produk per unit adalah sebesar Rp 15.432,5/unit. Biaya tetap pada masing-masing produk untuk produk jenis cherimen adalah sebesar Rp 7.177.086.394 dan produk jenis rumput laut adalah sebesar Rp 43.322.453. Jadi, jumlah keseluruhan biaya tetap pada produk adalah sebesar Rp 7.220.408.847.

Pengalokasian biaya variabel setelah di tambah dengan biaya bahan baku untuk produk jenis cherimen adalah $(21.469,5+134.189) \mathrm{Rp} 155.658,5$ per unit, sedangkan untuk produk rumput laut ( $20.213+116.214) \mathrm{Rp} 136.427$

Menyusun proyeksi laporan laba rugi

\section{Laporan laba rugi produk Cherimen}

Penjualan 901.936 x Rp 165.424

Biaya Variabel 902.924 x Rp 155.658,5

Margin Kontribusi

Biaya Tetap

Laba Bersih Sebelum Pajak
Rp 149.201.860.864

Rp 140.547.795.454 -

Rp 8.654.065.410

Rp 7.177.086.394 -

Rp $\quad 1.476 .979 .016$

\section{Laporan laba rugi produk Rumput laut}

Penjualan 5.795 x Rp 145.502

Biaya Variabel 5.798 x Rp 136.427

Margin Kontribusi

Biaya Tetap
Rp 843.184.090

Rp 791.003.746 -

Rp 52.180.344

Rp 43.322.453 - 
Laba Bersih Sebelum Pajak

$\mathrm{Rp} \quad 8.857 .891$

Menentukan Margin Kontribusi, Break Even Point, Margin Of Safety, Operating Leverage, dan Shut Down Point.

1. Margin Kontribusi

Margin kontribusi $(\mathrm{MK})=$ Penjualan - Biaya Variabel

Rasio margin kontribusi $=\frac{\text { margin kontribusi }}{\text { penjualan }}$

- Produk Cherimen

$$
\begin{aligned}
\text { Margin Kontribusi } & =\operatorname{Rp} 165.424-\mathrm{Rp} 155.658,5 \\
& =\operatorname{Rp} 9.765,5 \\
\text { Rasio Margin Kontribusi } & =\frac{\operatorname{Rp} 8.654 .065 .410}{\operatorname{Rp} 149.201 .860 .864} \times 100 \%=5,8 \%
\end{aligned}
$$

- Produk Rumput Laut

$$
\begin{aligned}
\text { Margin Kontribusi } & =\operatorname{Rp} 145.502-\mathrm{Rp} 136.427 \\
& =\operatorname{Rp} 9.075 \\
\text { Rasio Margin Kontribusi } & =\frac{\operatorname{Rp} 52.180 .344}{\operatorname{Rp} 843.184 .090} \times 100 \%=6,2 \%
\end{aligned}
$$

\section{Break Even Point (BEP) atau titik impas}

Setelah diketahui jumlah biaya tetap dan biaya variabel per unit maka dapat di cari titik impas (break even point) pada harga jual yang telah diramalkan.

Titik impas (unit) $=\frac{\text { Biaya tetap }}{\text { Margin kontribusi per unit }}$

Titik impas $(\mathrm{Rp})=\frac{\text { biaya tetap }}{\text { rasio margin kontribusi }}$

- Produk Cherimen

Titik impas (unit) $=\frac{\operatorname{Rp~7.177.086.394}}{\operatorname{Rp~9.765,5}}=734.943$

Titik impas $(\mathrm{Rp})=\frac{\operatorname{Rp} 7.177 .086 .394}{5,8 \%}=\operatorname{Rp} 123.742 .868 .862$

- Produk Rumput Laut

Titik impas (unit) $=\frac{\operatorname{Rp~43.322.453~}}{\operatorname{Rp~9.075}}=4.773$

Titik impas (Rp) $==\frac{\operatorname{Rp~} 43.322 .453}{6,2 \%}=\operatorname{Rp} 698.749 .242$

Jadi, titik impas untuk Produk Cherimen tahun 2016 adalah sebesar 734.943 unit dan Rp 123.742.868.862, sedangkan Produk Rumput Laut sebesar 4.773 unit dan Rp 698.749.242

\section{Margin Of Safety}

Besarnya margin of safety PT. Marinal Indoprima dapat di hitung sebagai berikut: Margin Of Safety $(\mathrm{Rp})=$ Penjualan - Titik Impas

- Produk Cherimen

$$
\begin{aligned}
\text { Margin Of Safety }(\mathrm{Rp}) & =\mathrm{Rp} 149.201 .860 .864-\mathrm{Rp} 123.742 .868 .862 \\
& =25.458 .992 .002
\end{aligned}
$$

- Produk Rumput Laut

$$
\begin{aligned}
\text { Margin Of Safety }(\mathrm{Rp}) & =\mathrm{Rp} 843.184 .080-\mathrm{Rp} 698.749 .242 \\
& =\mathrm{Rp} 144.434 .848
\end{aligned}
$$


Margin of safety untuk Produk Cherimen adalah sebesar Rp 25.458.992.002, sedangkan untu Produk Rumput Laut sebesar Rp 144.434.848 ini menunjukkan bahwa jika penjualan berkurang atau menyimpang lebih kecil dari hasil Margin of safety perusahaan akan mengalami kerugian atau berada diposisi yang kurang aman.

\section{Operating Leverage}

- Produk Cherimen

$$
\text { Operating Leverage }=\frac{\text { margin kontribusi }}{\text { laba bersih }}
$$

$$
\text { Operating Leverage }=\frac{\operatorname{Rp~8.654.065.410}}{\operatorname{Rp} 1.476 .979 .016}=5,86
$$

- Produk Rumput Laut

$$
\text { Operating Leverage }=\frac{\operatorname{Rp} 52.180 .344}{\operatorname{Rp} 8.857 .891}=60,83
$$

Operating leverage PT. Marinal Indoprima untuk produk Cherimen adalah sebesar 5,86 atau $586 \%$, sedangkan untuk produk Rumput Laut sebesar 60,83 atau 6.083\%.

\section{Shut Down Point atau Titik Penutupan Usaha}

- Produk Cherimen

$$
\text { Shut Down Point }=\frac{\text { Biaya tetap tunai }}{\text { rasio } \text { margin } \text { kontribusi }}
$$

$$
\text { Shut Down Point }=\frac{\mathrm{Rp} 6.025 .829 .711}{5,8 \%}=\mathrm{Rp} 103.893 .615 .707
$$

- Produk Rumput Laut

$$
\text { Shut Down Point }=\frac{\mathrm{Rp} 36.373 .217}{6,2 \%}=\operatorname{Rp} 586.664 .790
$$

Usaha pengolahan dihentikan jika penjualannya ada di bawah titik penutupan usaha (shut down point) untuk produk Cherimen sebesar Rp 103.893.615.707, sedangkan untuk produk Rumput Laut sebesar Rp 586.664.790.

\section{Analisis Target Laba}

Target laba yang diperkirakan untuk produk Cherimen adalah 15\% dari penjualan dan untuk produk Rumput Laut sebesar 5\% dari penjualan. Maka dapat dihitung penjualan untuk mencapai target laba pada masing-masing jenis produk adalah sebagai berikut:

1. Produk Cherimen

$$
\text { unit penjualan untuk mencapai target laba }=\frac{\text { biaya tetap }+ \text { target laba }}{\text { Margin Kontribusi per unit }}
$$

$$
\begin{aligned}
& =\frac{\operatorname{Rp} 7.177 .086 .394+15 \%(\operatorname{Rp} 149.201 .860 .864)}{R p 9.765,5} \\
& =\frac{\operatorname{Rp} 7.177 .086 .394+\operatorname{Rp} 22.380 .279 .130}{\operatorname{Rp} 9.765,5} \\
& =\frac{\operatorname{Rp} 29.557 .365 .524}{\operatorname{Rp} 9.765,5}=3.026 .713 \text { unit }
\end{aligned}
$$

Hal ini dapat dibuktikan dalam perhitungan berikut:

Penjualan (3.026.713 x Rp 165.424)

Biaya variabel $(3.026 .713 \times 155.658,5)$

Margi Kontribusi

Biaya tetap
Rp 500.690.966.604

$\underline{\mathrm{Rp} 471.133 .601 .081-}$

Rp 29.557.365.524

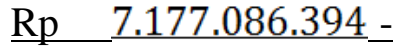


Laba bersih sebelum pajak

Rp $\quad 22.380 .279 .130$

Jadi, besarnya penjualan produk cherimen sesuai dengan target laba (15\%) dari penjualan sebesar 3.026.713 unit atau senilai Rp 500.690.966.604 dengan laba sebesar Rp 22.380.279.130

Produk Rumput Laut

$$
\begin{aligned}
& \text { Unit penjualan untuk mencapai target laba }=\frac{\text { biaya tetap }+ \text { target laba }}{\text { Margin Kontribusi per unit }} \\
& =\frac{\operatorname{Rp} 43.322 .453+5 \%(\operatorname{Rp} 843.184 .090)}{\operatorname{Rp} 9.075} \\
& =\frac{\operatorname{Rp} 43.322 .453+\operatorname{Rp} 42.159 .205}{\operatorname{Rp} 9.075} \\
& =\frac{\operatorname{Rp} 85.481 .658}{\operatorname{Rp} 9.075}=9.419 \text { unit }
\end{aligned}
$$

Hal ini dapat dibuktikan dalam perhitungan berikut:

Penjualan (9.419 x Rp 145.502)

Biaya variabel $(9.419 \times 136.427)$

Margi Kontribusi

Biaya tetap

Laba bersih sebelum pajak

\begin{tabular}{lc}
$R p$ & 1.370 .551 .199 \\
$R p$ & 1.285 .069 .541 \\
\hline$R p$ & 85.481 .658 \\
$R p$ & 43.322 .453 \\
$R$ & - \\
$R p$ & 42.159 .205
\end{tabular}

Besarnya penjualan produk cherimen sesuai dengan target laba (5\%) dari penjualan sebesar9.419 unit atau senilai Rp 1.370.551.199 dengan laba sebesar Rp 42.159.205.

\section{PENUTUP}

BEP untuk produk jenis cherimen 734.717 (unit), sedangkan untuk nilai rupiahnya sebesar $\mathrm{Rp}$ 123.742.868.862. BEP untuk produk jenis rumput laut adalah sebesar 4.773 (unit) dengan nilai rupiah sebesar Rp 698.749.242 Pada tahun penelitian 2015, perusahan telah memproduksi di atas titik impas.Margin Of Safety Jenis produk Cherimen adalah sebesar Rp 25.458.992.002, dan untuk produk rumput laut sebesar Rp 144.434.848, Jika penjualan jenis cherimen dan rumput laut berkurang dari hasil Margin Of Safety, maka akan mengalami kerugian. Tingkat Operating Laverage PT Marinal IndoPrima untuk produk Cherimen sebesar $586 \%$ dan produk Rumput laut sebesar $6.083 \%$, jadi setiap kenaikan $1 \%$ dapat menambah atau berpengaruh pada pendapatan laba dari penjualan perusahaan. Berdasarkan perhitungan Shut Down Point, pengolahan produk cherimen dan rumput laut harus dihentikan jika penjualan berada dititik penutupan usaha Rp 103.893.615.707 (produk cherimen) dan sebesar Rp 586.664.790 (produk rumput laut).

PT Marinal Indoprima sebaiknya mempertimbangkan peningkatan ramalan penjualan tahun 2016 yang diperhitungkan dalam penelitian ini untuk mendapatkan laba yang maksimal. Dalam melakukan penelitian ini peneliti memberikan saran terhadap peneliti selanjutnya agar lebih baik lagi dalam mengefesiensi waktu penelitian, sehingga hasil penelitian akan lebih baik lagi. Selain itu, sebaiknya peneliti selanjutnya, mempertimbangkan untuk menggunakan kajian literatur yang lebih banyak.

\section{DAFTAR PUSTAKA}

Bungi, Burhan. 2005. Metodologi Penelitian Kuantitatif. Edisi Pertama Jakarta. Penerbit Prenada Media Group. 
Bustami, Bastian dan Nurlela. 2007. Akuntansi Biaya. Edisi Pertama Yogyakarta. Penerbit Graha ilmu.

Carter \& Usry. 2005. Akuntansi Biaya. Edisi 13 Jakarta. Penerbit Salemba Empat.

Don R. Hansen, Maryanne M.Mowen. 2005. Management Accounting. Edisi 7 Jakarta. Penerbit Salemba.

Duyo, Sheila F.. 2013. Analisis Cost Volume Profit Untuk Perencanaan Laba Pada Hotel Sintesa Peninsula Manado. Skripsi Fakultas Ekonomi dan Bisnis, Jurusan Akuntansi. Universitas Sam Ratulangi Manado.

Garrison, Ray H., Eric W. Noreen. 2000. Akuntansi Manajerial Jakarta. Penerbit Selemba Empat.

Hadi, Syamsul. 2006. Metodelogi Penelitian Kuantitatif, Untuk Akuntansi dan Keuangan. Yogyakarta. Ekonosia.

Kusnadi, dkk. 2005. Akuntansi Manajemen (Komprehensif, Tradisional \& Kontemporer). Malang. Universitas Brawijaya.

Mulyadi. 2005. Akuntansi Biaya. Edisi 5. Yogyakarta. Penerbit Akademi Manajemen Perusahaan YKPN.

Nazir, Moh.. 2009. Metode Penelitian. Jakarta. Penerbit Ghalia Indonesia.

Pelawiten, Atika, dkk. 2014. Analisis Cost Volume Profit Untuk Perencanaan Laba Pada UD. Gladys Bakery. Skripsi Fakultas Ekonomi dan Bisnis, Jurusan Akuntansi. Universitas Sam Ratulangi.

Riduwan. 2009. Dasar-Dasar Statistika. Bandung. Penerbit Alfabeta.

Rudianto. 2013. Akuntansi Manajemen. Jakarta. Penerbit Erlangga.

Samryn. 2013. Akuntasi Manajemen. Edisi Revisi Jakarta. Penerbit Kencana.

Sugiyono. 2011. Metode Penelitian Kuantitatif Kualitatif dan R\&D. Bandung. Penerbit Alfabeta.

Wiharjo, Nelly. 2011. Analisis Hubungan Cost-Volume-Profit (CVP) untuk Perencanaan Laba pada Hotel Losari Beach. Skripsi Fakultas Ekonomi, Jurusan Akuntansi. Universitas Hasanuddin Makassar.

Yamit, Zulian. 2003. Manajemen Produksi Dan Operasi. Yogyakarta. Penerbit Ekonesia. 